\title{
Author Correction: A large-scale test of the link between intergroup contact and support for social change
}

Tabea Hässler (iD, Johannes Ullrich (iD, Michelle Bernardino (D), Nurit Shnabel (iD, Colette Van Laar, Daniel Valdenegro, Simone Sebben (D), Linda R. Tropp, Emilio Paolo Visintin (D), Roberto González, Ruth K. Ditlmann, Dominic Abrams, Hema Preya Selvanathan (D), Marija Brankovic (D), Stephen Wright, Jorina von Zimmermann, Michael Pasek (D), Anna Lisa Aydin, Iris Žeželj (D), Adrienne Pereira, Nóra Anna Lantos (D), Mario Sainz (D), Andreas Glenz, Hana Oberpfalzerová (D), Michal Bilewicz, Anna Kende (D), Olga Kuzawinska (D), Sabine Otten, Edona Maloku (D), Masi Noor, Pelin Gul (D), Jessica Pistella (D), Roberto Baiocco (D), Margareta Jelic, Evgeny Osin (D), Orly Bareket (D), Dinka Corkalo Biruski D, Jonathan E. Cook (D), Maneeza Dawood, Lisa Droogendyk, Angélica Herrera Loyo, Kaltrina Kelmendi $(\mathbb{D}$ and Luiza Mugnol Ugarte $\mathbb{D}$

Correction to: Nature Human Behaviour https://doi.org/10.1038/s41562-019-0815-z, published online 27 January 2020.

In the version of this article initially published, author Lisa Droogendyk's affiliation was incorrect. It should have read "School of Social and Life Sciences, Sheridan College, Oakville, Ontario, Canada”. The error has been corrected in the HTML and PDF versions of the article.

Published online: 23 June 2020

https://doi.org/10.1038/s41562-020-0915-9

(C) The Author(s), under exclusive licence to Springer Nature Limited 2020 